\title{
A broad-host-range vector of incompatibility group $Q$ can work as a plasmid vector in Neisseria meningitidis: a new genetical tool
}

\author{
Hideyuki Takahashi and Haruo Watanabe
}

Author for correspondence: Hideyuki Takahashi. Tel: +8135285 1111. Fax: +81352851163. e-mail: hideyuki@nih.go.jp

Department of Bacteriology, National Institute of Infectious Diseases, Toyama 1-23-1, Shinjuku-ku, Tokyo 162-8640, Japan

\begin{abstract}
Plasmid pHT128, a derivative of the broad-host-range IncQ vector pGSS33, was successfully introduced into Neisseria meningitidis. Under optimal conditions, pHT128 was transferred from Escherichia coli to $N$. meningitidis by triparental conjugation at a frequency of $1^{-5}-10^{-6}$. The copy number of pHT128 in $\boldsymbol{N}$. meningitidis was almost the same as in $E$. coli, in which the copy number of IncQ plasmids per chromosome is estimated to be 10 . pHT128 was maintained as an episome in $\boldsymbol{N}$. meningitidis in the presence of chloramphenicol, a marker of the plasmid. It was also shown that an opc or pilE1 gene cloned on pHT128 could be expressed in $\boldsymbol{N}$. meningitidis under control of the tac promoter and could complement a mutation of opc or pilE1, respectively. In addition, the conjugational introduction of pHT128 into $N$. meningitidis was demonstrated to be independent of natural transformation competence. All the results indicate that pHT128 is a useful vector for $N$. meningitidis as a new genetical tool.
\end{abstract}

Keywords: IncQ plasmid, triparental conjugation, restriction/modification systems, complementation

\section{INTRODUCTION}

Neisseria meningitidis is a Gram-negative diplococcus pathogen that colonizes the nasopharynx. It eventually spreads into the bloodstream, where it causes septicaemia and, furthermore, induces meningitis when it reaches the cerebrospinal fluid. Although some of the factors involved in pathogenesis, such as Opa (reviewed by Dehio et al., 1998; Nassif et al., 1999), Opc, pili (reviewed by Nassif et al., 1999) and the capsule (reviewed by Vogel et al., 1999), have been revealed, many problems still remain to be resolved (reviewed by Nassif \& So, 1995; Nassif et al., 1999). A scarcity of genetic systems available for the meningococcus is one of the reasons hampering the development of genetic analysis (Kupsch et al., 1996).

Some R-plasmids in Neisseria gonorrhoeae have been used for the construction of vector plasmids (Stein et al., 1983; Piffaretti et al., 1988; Stein, 1989; Kupsch et al.,

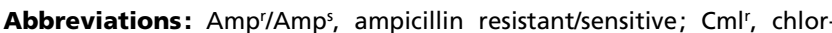
amphenicol resistant; Ermr, erythromycin resistant; $\mathrm{Kan}^{\mathrm{r}} / \mathrm{Kan}^{\mathrm{s}}$, kanamycin resistant/sensitive; Tetr/Tet ${ }^{s}$, tetracycline resistant/sensitive; Str'/Str ${ }^{s}$, streptomycin resistant/sensitive.
}

1996). Although it is well known that N. gonorrhoeae is genetically very closely related to $N$. meningitidis and a few plasmids were speculated to transfer from $N$. gonorrhoeae to N. meningitidis (Dillon et al., 1983; Ison et al., 1986; Knapp et al., 1988), most of the plasmids in N. gonorrhoeae were not applicable to N. meningitidis (Genco et al., 1984; Roberts et al., 1989). As far as we know, only two plasmids, a $4 \cdot 5 \mathrm{Mb}$ R-plasmid of $\mathrm{N}$. gonorrhoeae and pMGC10, a derivative of shuttle vector pLES2, could be transferred to N. meningitidis (Ikeda et al., 1986; Nassif et al., 1991). On the other hand, some R-plasmids have been also found in N. meningitidis (Bhatti et al., 1981; Pintado et al., 1985; Rotger et al., 1986; Facinelli \& Varaldo, 1987; Roberts et al., 1989). One of them was supposed to belong to the family of RSF1010, which is a broad-host-range vector of incompatibility group Q (IncQ) (Pintado et al., 1985).

IncQ plasmids such as RSF1010 and R300B (Sharpe, 1984) are found among Gram-negative bacteria (Barth et al., 1981). IncQ plasmids are not self-transmissible but mobile with the help of IncP plasmids. Since R300B is relatively small $(8.68 \mathrm{~kb}$; Meyer et al., 1982) and low in copy number (about 10 copies per E. coli genome; Barth \& Grinter, 1974), it has been utilized for the construction of vectors (Sharpe, 1984). pGSS33 is one of 
the derivatives of R300B and has been used as a cloning vector.

In this paper, we report that pHT128, a derivative of pGSS33, can be successfully introduced into $N$. meningitidis.

\section{METHODS}

Media and growth conditions. N. meningitidis was stocked in frozen solution (Suker et al., 1994) at $-80{ }^{\circ} \mathrm{C}$ and routinely grown on GC agar plates, [GC medium agar (BectonDickinson) supplemented with $1 \%$ IsoVitaleX enrichment (Becton-Dickinson)], at $37{ }^{\circ} \mathrm{C}$ in $5 \% \mathrm{CO}_{2}$. Trypticase soy broth (TSB; Becton-Dickinson) supplemented with $1 \%$ IsoVitaleX enrichment was used for the isolation of the plasmids in N. meningitidis. E. coli was grown on $\mathrm{L}$ plates or in $\mathrm{L}$ broth liquid culture at $37^{\circ} \mathrm{C}$. When required, antibiotics were added at the following concentrations. For $N$. meningitidis, chloramphenicol at $5 \mu \mathrm{g} \mathrm{ml}^{-1}$, erythromycin at $4 \mu \mathrm{g} \mathrm{ml}^{-1}$, ampicillin at $1 \mu \mathrm{g} \mathrm{ml}^{-1}$. VCN (V, vancomycin; C, colistin; $\mathrm{N}$, nystatin) inhibitor (Becton-Dickinson) was added to a final concentration of $1 \%$ to select $N$. meningitidis transconjugants. For E. coli, chloramphenicol was added at $10 \mu \mathrm{g} \mathrm{ml}^{-1}$, kanamycin at $50 \mu \mathrm{g} \mathrm{ml}^{-1}$, tetracycline at $15 \mu \mathrm{g} \mathrm{ml}^{-1}$, ampicillin at $50 \mu \mathrm{g} \mathrm{ml}^{-1}$ and erythromycin at $150 \mu \mathrm{g} \mathrm{m} \mathrm{m}^{-1}$. IPTG was added at a final concentration of $1 \mathrm{mM}$. The growth and concentration of bacteria were measured by monitoring the $\mathrm{OD}_{600}$.

Strains. Strains used in this study are listed in Table 1. HT1037 was constructed as follows. A $1.3 \mathrm{~kb}$ fragment containing the $o p c$ gene with BamHI and EcoRI linkers was amplified from H44/76 chromosomal DNA by PCR. All the PCR reactions done in this study were performed in a Gene Amp PCR System 2400 (Applied Biosystems) using ExTaq DNA polymerase (Takara Shuzo). The resulting DNA fragment was digested with BamHI and EcoRI, then cloned in the BamHI and EcoRI sites of pUC118 to construct pHT3 (see also Table 2). A blunted $1 \cdot 2 \mathrm{~kb}$ HindIII-HindIII fragment containing the erm $\mathrm{C}$ gene isolated from pHT24 was inserted into the blunted EcoT14I sites, located at $196 \mathrm{bp}$ and 526 bp downstream from the start codon of the opc gene, to generate pHT148. pHT148 DNA (500 ng) linearized by digestion with SalI, the site of which is located on the vector, was transformed into H44/76 and $\mathrm{Erm}^{\mathrm{r}}$ clones were isolated, resulting in an $o p c$ deletion mutant of $\mathrm{H} 44 / 76$.
HT1033 was constructed as follows. A $1 \mathrm{~kb}$ fragment containing the pilE1 gene with BamHI and EcoRI linkers was amplified by PCR and cloned in the BamHI and EcoRI sites of pUC119 to construct pHT65. A blunted $1 \cdot 2 \mathrm{~kb}$ HindIIIHindIII fragment containing the erm $C$ gene isolated from pHT24 was inserted into the BstXI site, located at $135 \mathrm{bp}$ downstream from the start codon of the pilE1 gene, to generate pHT72. pHT72 (500 ng) linearized by digestion with EcoRI was transformed into NIID57 and Erm ${ }^{\mathrm{r}}$ clones were isolated, resulting in a pilE1 insertion mutant of NIID57.

Plasmids. Plasmids used in this study are listed in Table 2. A $\mathrm{Kan}^{\mathrm{s}} \mathrm{Tet}^{\mathrm{s}}$ derivative of RP4 (Pansegrau \& Lanka, 1987), pHT13, was constructed as follows. First, RP4 digested with HindIII and HpaI was blunted with a DNA blunting kit (Takara Shuzo) and self-ligated by DNA ligation kit version 2 (Takara Shuzo) to generate pHT12 $\left(\mathrm{Kan}^{\mathrm{s}}\right)$. In the next step, pHT12 digested with BglII and partially digested with StuI was blunted, self-ligated and transformed to DH5 $\alpha$ to select $\mathrm{Amp}^{\mathrm{r}} \mathrm{Kan}^{\mathrm{s}} \mathrm{Tet}^{\mathrm{s}}$ clones. The resultant plasmid was renamed pHT13 and used as a helper for conjugation of a derivative of pGSS33 (Fig. 1a) from E. coli to N. meningitidis. pHT128 (Fig. 1b), a Str ${ }^{\mathrm{s}}$ and Amp $\mathrm{p}^{\mathrm{s}}$ derivative of pGSS33, was constructed by removing the PstI-SacI region after blunting. pHT160 (see Fig. 4c) was constructed as follows. A $0.9 \mathrm{~kb}$ fragment containing the entire $o p c$ coding region with EcoRI and BamHI linkers was amplified by PCR and cloned in the BamHI and EcoRI sites of pTTQ18 (Stark, 1987) to construct pHT157. A $4 \cdot 3 \mathrm{~kb}$ AlwNI-ScaI fragment of pHT157 containing both the tac promoter fused to the $o p c$ gene and the $l a c I^{q}$ gene was blunted and cloned in the PstI and SacI sites of pGSS33 after blunting. The resultant plasmid was pHT160. pHT161 (Fig. 4a) was constructed as follows. A $0.6 \mathrm{~kb}$ fragment containing the entire pilE1 coding region was amplified by PCR with the corresponding primers, which contained the EcoRI linker tagged by six CAC tandem repeats $\left(\mathrm{His}_{6}\right)$ and a $S m a \mathrm{I}$ linker. The amplified fragment was cloned in the EcoRI and SmaI sites of pTTQ18 to construct pHT68. A $4 \mathrm{~kb}$ AlwNI-ScaI fragment of pHT68 containing both the tac promoter fused to

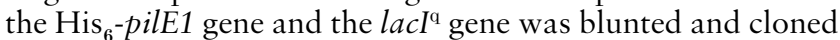
in the PstI and SacI sites of pGSS33 after blunting. The resultant plasmid was $\mathrm{pHT} 161$.

All of the primers to amplify N. meningitidis genes used in this study were designed by reference to the TIGR N. meningitidis database (http://www.tigr.org/).

DNA transfer. For transformation by natural competence, $N$.

Table 1. Strains used in this study

\begin{tabular}{|c|c|c|}
\hline Strain & Genotype, pedigree of strain & Source \\
\hline \multicolumn{3}{|l|}{ E. coli } \\
\hline $\mathrm{DH} 5 \alpha$ & $\begin{array}{l}\text { supE44 } \Delta \text { lacU169 ( } \phi 80 d l a c Z \Delta M 15) \text { hsdR17 recA1 } \\
\text { deoR endA1 gyrA96 thi-1 relA1 }\end{array}$ & Takara Shuzo \\
\hline LE392 & $\begin{array}{l}\text { supE44 supF58 hsdR514 galK2 galT22 metB1 } \\
\text { trpR55 lacY1 }\end{array}$ & Promega \\
\hline \multicolumn{3}{|c|}{ N. meningitidis } \\
\hline $\mathrm{H} 44 / 76$ & $\begin{array}{l}\text { Serogroup B, a representative isolate of the } \\
\text { Norwegian group B epidemic }\end{array}$ & $\begin{array}{l}\text { National Institute of } \\
\text { Public Health, Norway }\end{array}$ \\
\hline NIID57 & $\begin{array}{l}\text { Serogroup B, a clinical isolate from a Japanese } \\
\text { healthy carrier }\end{array}$ & This study \\
\hline HT1037 & $\mathrm{H} 44 / 76 \Delta o p c:: \mathrm{ermC}$ & This study \\
\hline HT1033 & NIID57 pilE1:: ermC & This study \\
\hline
\end{tabular}


Table 2. Plasmids used in this study

\begin{tabular}{|c|c|c|}
\hline Plasmid & Genotype pedigree and markers & Source \\
\hline pUC18 & Cloning vector; $\mathrm{Amp}^{\mathrm{r}}$ & Takara Shuzo \\
\hline pUC118 & Cloning vector; Amp ${ }^{r}$ & Takara Shuzo \\
\hline pUC119 & Cloning vector; $A m p^{r}$ & Takara Shuzo \\
\hline pTnMax2 & Plasmid for in vitro mutagenesis; $\mathrm{Erm}^{\mathrm{r}}$ & Hass et al. (1993) \\
\hline pHT24 & $\begin{array}{l}\text { Derivative of pUC18 containing a } 1 \cdot 2 \mathrm{~kb} \text { HindIII-HindIII } \\
\text { fragment that carries the ermC gene of pTnMax2; Amp }{ }^{r} \\
\text { Erm }^{r}\end{array}$ & This study \\
\hline pHT3 & $\begin{array}{l}\text { Derivative of pUC118 containing a } 1.3 \mathrm{~kb} \mathrm{BamHI-EcoRI} \\
\text { fragment that carries the } o p c \text { gene; Amp }{ }^{\mathrm{r}}\end{array}$ & This study \\
\hline pHT148 & $\begin{array}{l}\text { Derivative of pHT3 in which the ermC gene was inserted in } \\
\text { EcoT14I sites of the opc gene; } \mathrm{Amp}^{\mathrm{r}} \mathrm{Erm}^{\mathrm{r}}\end{array}$ & This study \\
\hline pHT65 & $\begin{array}{l}\text { Derivative of pUC119 containing a } 1 \mathrm{~kb} \mathrm{BamHI-EcoRI} \\
\text { fragment that carries the pilE1 gene; } \mathrm{Amp}^{\mathrm{r}}\end{array}$ & This study \\
\hline pHT72 & $\begin{array}{l}\text { Derivative of pHT65 in which the ermC gene was inserted } \\
\text { in the BstXI site of the pilE1 gene; } \text { Amp }^{r} \text { Erm }^{r}\end{array}$ & This study \\
\hline RP4 & Broad-host-range IncP vector; $\mathrm{Amp}^{\mathrm{r}} \mathrm{Kan}^{\mathrm{r}} \mathrm{Tet}^{\mathrm{r}}$ & $\begin{array}{l}\text { Pansegrau \& Lanka } \\
\text { (1987) }\end{array}$ \\
\hline pHT12 & 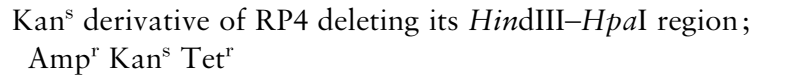 & This study \\
\hline pHT13 & $\begin{array}{l}\text { Tet }{ }^{\mathrm{s}} \text { derivative of } \mathrm{pHT} 12 \text { deleting its } B g l \mathrm{II}-S t u \mathrm{I} \text { region; } \\
\mathrm{Amp}^{\mathrm{r}} \mathrm{Kan}^{\mathrm{s}} \mathrm{Tet}^{\mathrm{s}} \text {; a helper plasmid used for conjugation }\end{array}$ & This study \\
\hline pGSS33 & Broad-host-range IncQ vector; $\operatorname{Str}^{\mathrm{r}} \mathrm{Amp}^{\mathrm{r}} \mathrm{Cml}^{\mathrm{r}} \mathrm{Tet}^{\mathrm{r}}$ & Sharpe (1984) \\
\hline pHT128 & $\begin{array}{l}\text { Str }{ }^{\mathrm{s}} \text { Amp }{ }^{\mathrm{s}} \text { derivative of } \mathrm{pGSS} 33 \text { deleting its PstI-SacI } \\
\text { region; } \text { Str }^{\mathrm{s}} \mathrm{Amp}^{\mathrm{s}} \mathrm{Cml}^{\mathrm{r}} \mathrm{Tet}^{\mathrm{r}}\end{array}$ & This study \\
\hline pTTQ18 & Expression vector under control of the $t a c$ promoter; $A m p^{r}$ & Stark (1987) \\
\hline pHT157 & $\begin{array}{l}\text { Derivative of pTTQ18 containing the } o p c \text { gene under } \\
\text { control of the tac promoter; Amp }{ }^{r}\end{array}$ & This study \\
\hline pHT160 & $\begin{array}{l}\text { Derivative of pGSS33 containing a } 4.3 \mathrm{~kb} \text { AlwNI-ScaI } \\
\text { fragment of pHT157; } \text { Cml }^{\mathrm{r}} \text { Tet }^{\mathrm{r}}\end{array}$ & This study \\
\hline pHT68 & $\begin{array}{l}\text { Derivative of pTTQ18 containing the His-tagged pilE1 gene } \\
\text { under control of the tac promoter; Amp }{ }^{r}\end{array}$ & This study \\
\hline pHT161 & $\begin{array}{l}\text { Derivative of pGSS33 containing a } 4 \mathrm{~kb} \text { AlwNI-ScaI } \\
\text { fragment of pHT } 68 ; \mathrm{Cml}^{\mathrm{r}} \mathrm{Tet}^{\mathrm{r}}\end{array}$ & This study \\
\hline
\end{tabular}

meningitidis was transformed as previously described (Ryll et al., 1997). Plasmids were linearized prior to transformation unless otherwise stated.

Electroporation for Neisseria was performed as follows. N. meningitidis grown on GC agar plates at $37^{\circ} \mathrm{C}$ in $5 \% \mathrm{CO}_{2}$ was scraped and suspended in $30 \mathrm{ml} \mathrm{TSB}$ supplemented with $1 \%$ IsoVitaleX enrichment to adjust the supension to $\mathrm{OD}_{600}$ $0 \cdot 1$. The bacteria were cultured at $37^{\circ} \mathrm{C}$ with shaking to $\mathrm{OD}_{600}$ of 0.6 and then the cells were chilled and harvested by centrifugation at $4{ }^{\circ} \mathrm{C}$. The pellets were rinsed with $1 \mathrm{ml}$ icecold $10 \%(\mathrm{w} / \mathrm{v})$ glycerol three times and the cells were resuspended to a final volume of $60 \mu \mathrm{l}$ in ice-cold $10 \%$ glycerol. A $20 \mu \mathrm{l}$ sample of the cell suspension was mixed with up to $1 \mu \mathrm{g}$ of plasmid DNA and electroporation was performed under the following optimized conditions: electric field strength, capacitance and resistance were $1.25 \mathrm{kV}, 25 \mu \mathrm{F}$ and $400 \Omega$, respectively, when using a $0 \cdot 1 \mathrm{~cm}$ electrode gap cuvette (Bio-Rad) with the Gene Pulser (Bio-Rad). After being electroporated, cells were incubated in $1 \mathrm{ml}$ TSB supplemented with $1 \%$ IsoVitaleX enrichment, $10 \mathrm{mM} \mathrm{MgCl}_{2}$ and $0.4 \%$ glucose at $37^{\circ} \mathrm{C}$ for $1 \mathrm{~h}$. The cells harvested by centrifugation were spread on GC agar plates with $5 \mu \mathrm{g}$ chloramphenicol $\mathrm{ml}^{-1}$ and incubated at $37^{\circ} \mathrm{C}$ in $5 \% \mathrm{CO}_{2}$ for $18 \mathrm{~h}$.
For conjugation, N. meningitidis grown on GC agar plates at $37{ }^{\circ} \mathrm{C}$ in $5 \% \mathrm{CO}_{2}$ was scraped and suspended in TSB to adjust the supension to $\mathrm{OD}_{600} 0 \cdot 25$. In order to transfer a cloned vector plasmid from E. coli to $N$. meningitidis, we used triparental conjugation. Overnight cultures of LE392 harbouring vector plasmid pGSS33 or pHT128, LE392 harbouring a helper plasmid $\mathrm{pHT} 13$ and $N$. meningitidis suspension prepared as described above were mixed at a volume ratio of $1: 1: 2$ and then filtered through $0.45 \mu \mathrm{m}$ membrane filters (Millipore) by use of a syringe. The filters were washed with $2 \mathrm{ml} \mathrm{TSB}$, then incubated on GC agar plates at $37^{\circ} \mathrm{C}$ in $5 \% \mathrm{CO}_{2}$ for $8 \mathrm{~h}$. Bacteria on the filters were washed out with $1 \mathrm{ml}$ TSB. The bacteria, harvested by centrifugation, were then spread on $\mathrm{GC}$ agar plates containing $5 \mu \mathrm{g}$ chloramphenicol $\mathrm{ml}^{-1}$ and $1 \% \mathrm{VCN}$ inhibitor and incubated at $37^{\circ} \mathrm{C}$ in $5 \% \mathrm{CO}_{2}$ for $24 \mathrm{~h}$. Transconjugants of $\mathrm{N}$. meningitidis were picked up and streaked on the same kind of plates to isolate a single clone.

Checking the maintenance of pHT128 in $N$. meningitidis. NIID57 harbouring pHT128 grown on a GC agar plate or E. coli strain LE392 harbouring pHT128 on an L agar plate was scraped and suspended in $10 \mathrm{ml}$ TSB supplemented with $1 \%$ IsoVitaleX enrichment at an $\mathrm{OD}_{600}$ of 0.2 and cultured at 
(a)

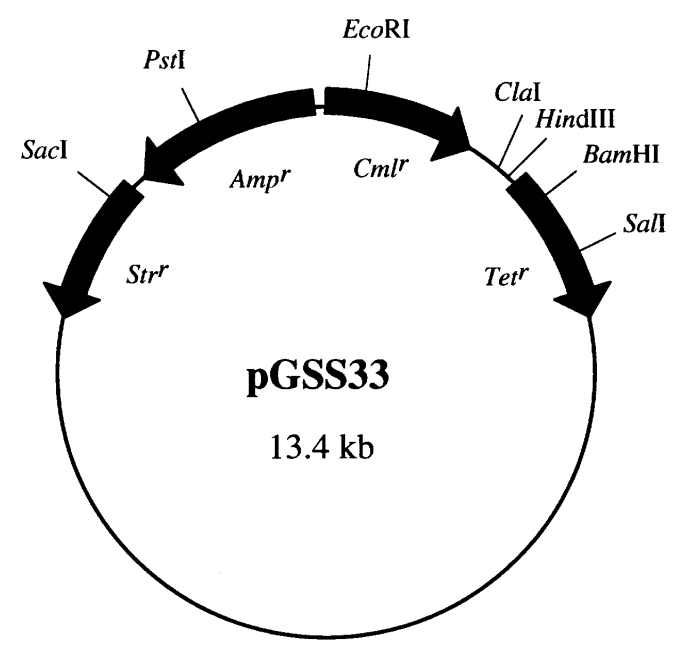

(b)

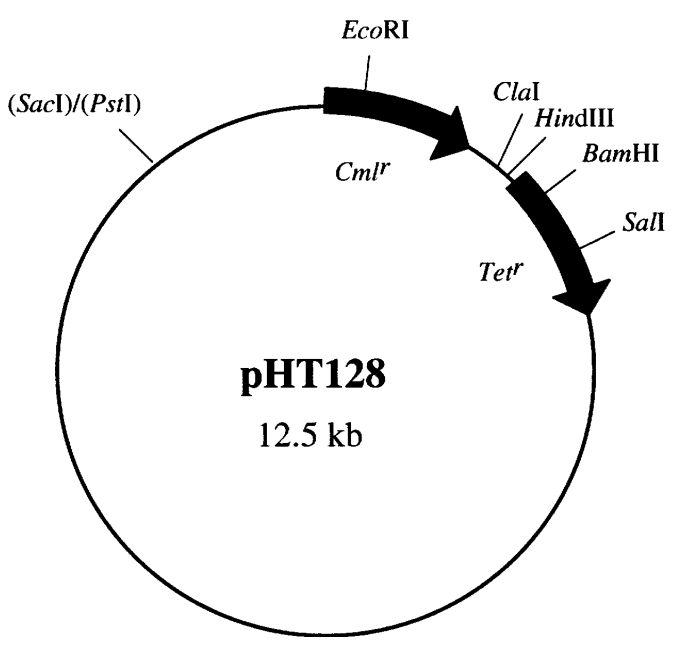

Fig. 1. Restriction maps of pGSS33 (a) and pHT128 (b). The sites of major restriction enzymes are shown. pHT128 was constructed as described in Methods.

$37^{\circ} \mathrm{C}$ with shaking for $24 \mathrm{~h}$. One millilitre of the bacterial culture was added to $9 \mathrm{ml}$ fresh medium and continuously cultured under the same conditions as described above. This step was repeated a total of four times. Each time, appropriate dilutions of the bacterial culture were spread on GC agar plates with or without $5 \mu \mathrm{g}$ chloramphenicol ml ${ }^{-1}$ for NIID57 and $\mathrm{L}$ agar plates with or without $10 \mu \mathrm{g}$ chloramphenicol ml ${ }^{-1}$ for LE392 to count the number of bacteria harbouring $\mathrm{pHT} 128$ and the total number of bacteria, respectively. The number of bacterial generations was determined graphically from the values of $\mathrm{OD}_{600}$.

Isolation of DNA. Mini-preparation of plasmid from E. coli was carried out by Wizard Plus SV Minipreps DNA Purification systems (Promega). Isolation of plasmids from $N$. meningitidis transconjugants and E. coli transformants cultured in more than $1 \mathrm{ml}$ of medium was essentially as described by Kado \& Liu (1981).

For the isolation of total DNA, N. meningitidis was cultured in the same conditions as described in the preceding section except that chloramphenicol was added during the culturing.
Total DNA from N. meningitidis transconjugants was isolated as described by Suker et al. (1994).

Southern blotting. One microgram of the total DNA of $N$. meningitidis was digested with ClaI and analysed on a $0.8 \%$ agarose gel. The gel was treated with $0 \cdot 25 \mathrm{M} \mathrm{HCl}$ followed with $0.5 \mathrm{M} \mathrm{NaOH}$ and then transferred to Hybond-N+ membrane (Amersham). The resultant membrane was hybridized with the cat gene of pHT128 as a probe and signals were detected by ECL direct nucleic acid labelling and detection systems (Amersham) according to the manufacturer's protocol.

Preparation of antibody for pili. A peptide encompassing residues 41-55 (EGQKSAVTEYYLNHG) of pilin, a region recognized by the monoclonal antibody SM1 made by Virji and co-workers (Virji \& Heckels, 1983; Virji et al., 1989), was synthesized. An antiserum specific for the oligopeptide was obtained by immunization of rabbits with the peptide coupled to keyhole limpet haemocyanin using $m$-maleimidobenzoyl$\mathrm{N}$-hydroxysuccinimide ester (MBS).

Western blotting. The N. meningitidis cells were suspended in $1 \times$ SDS buffer $(2 \%$ SDS, $5 \%$ 2-mercaptoethanol, $62.5 \mathrm{mM}$ Tris/HCl pH $8 \cdot 0,10 \%$ glycerol, $0 \cdot 1 \%$ Bromophenol blue) and adjusted to $\mathrm{OD}_{600} 10$. After boiling for $5 \mathrm{~min}, 2.5 \mu \mathrm{l}$ samples were subjected to 12 or $15 \%$ SDS-polyacrylamide gel electrophoresis. Western blotting was performed with SequiBlot PVDF membrane (Bio-Rad) and Horizeblot (ATTO). The resulting membrane was soaked in PBS containing $0.1 \%$ Tween 20 (T-PBS) and $5 \%$ skim milk at room temperature for $1 \mathrm{~h}$ with gentle shaking. The membrane was incubated with $10^{3}$-fold diluted anti-pili serum or $10^{4}$-fold diluted monoclonal antibody against Opc (B306; Achtman et al., 1988) at room temperature for $1 \mathrm{~h}$. After washing the membrane in T-PBS for 10 min three times, it was incubated with 2000-fold diluted horseradish-peroxidase-conjugated anti-rabbit or anti-mouse antibody (Boehringer). After washing the membrane in T-PBS for 10 min three times, signals were detected by ECL detection kit (Boehringer) and ECL film (Boehringer).

\section{RESULTS}

\section{Transconjugation of $\mathrm{pHT} 128$ from $E$. coli to N. meningitidis}

To check growth inhibition by antibiotics, $N$. meningitidis strains H44/76 and NIID57 were incubated on GC agar plates containing various concentrations of antibiotics at $37^{\circ} \mathrm{C}$ in $5 \% \mathrm{CO}_{2}$ for $18 \mathrm{~h}$. Growth of both strains was completely inhibited by $5 \mu \mathrm{g}$ chloramphenicol ml $\mathrm{m}^{-1}, 1 \mu \mathrm{g}$ ampicillin $\mathrm{ml}^{-1}$ and $4 \mu \mathrm{g}$ erythromycin $\mathrm{ml}^{-1}$ but not clearly inhibited by $50 \mu \mathrm{g}$ kanamycin $\mathrm{ml}^{-1}$ or $2 \mu \mathrm{g}$ tetracycline $\mathrm{ml}^{-1}$ (data not shown). As penicillin has been used as a first choice of antibiotic for the treatment of meningococcaemia, we chose to use the chloramphenicol-resistance gene as a selective marker in this study.

We tried to introduce the IncQ plasmid pHT128 into N. meningitidis strain NIID57 by three methods: transformation by natural competence, electroporation and conjugation. Although no $\mathrm{Cml}^{\mathrm{r}}$ colonies were obtained with transformation by natural competence or electroporation, some $\mathrm{Cml}^{\mathrm{r}}$ colonies appeared when triparental conjugation was used to transfer pHT128 from E. coli to NIID57. To optimize the conditions of triparental 

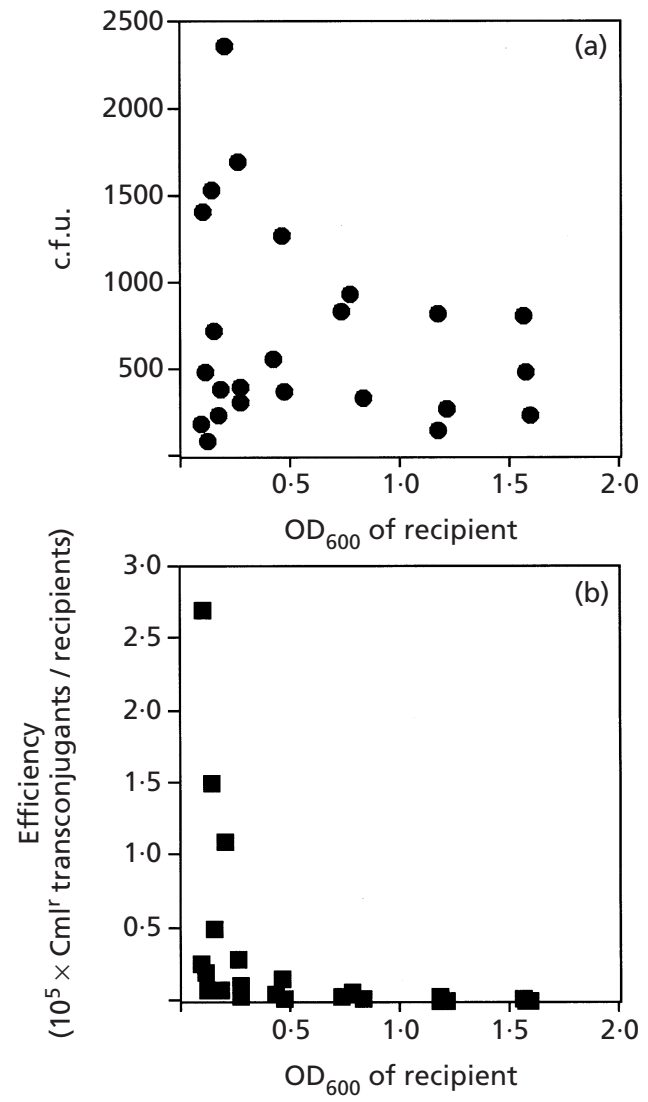

Fig. 2. Effect of concentration of the recipient on the efficiency of conjugation. (a) Number of $\mathrm{Cml}^{\mathrm{r}}$ colonies appearing on plates versus $O_{600}$ of recipient. (b) Conjugation efficiency (number of $\mathrm{Cml}^{\mathrm{r}}$ transconjugants/number of recipients) versus $\mathrm{OD}_{600}$ of recipient.

conjugation, we changed the concentration of the recipient strain NIID57 and found that the efficiency of conjugation seemed to be highest at a density of $\mathrm{OD}_{600}$ $0 \cdot 2-0 \cdot 3$, although the number of $\mathrm{Cml}^{\mathrm{r}}$ transconjugants seemed to be almost equal (about $10^{3}$ clones) independent of the concentration of the recipient strain (Fig. 2a). The efficiency of transconjugation was calculated to be about $10^{-5}$ (transconjugants/recipients) under the best conditions (Fig. 2b). As a similar result was obtained with $N$. meningitidis strain $\mathrm{H} 47 / 76$ as recipient (data not shown), pHT128 seems to be introduced into $N$. meningitidis serogroup B regardless of strain specificity.

Since no colonies appeared when transconjugants were selected on ampicillin-containing plates (data not shown), it was speculated that the IncP plasmid used as a helper plasmid could not be transferred or replicated in N. meningitidis.

\section{Isolation of pHT128 from $N$. meningitidis}

To confirm the existence of pHT128 in N. meningitidis, we isolated the plasmids from $\mathrm{Cm}^{\mathrm{r}} \mathrm{N}$. meningitidis transconjugants. Plasmids the same size as pHT128 $(12 \mathrm{~kb})$ were isolated from all the $\mathrm{Cml}^{\mathrm{r}} \mathrm{N}$. meningitidis
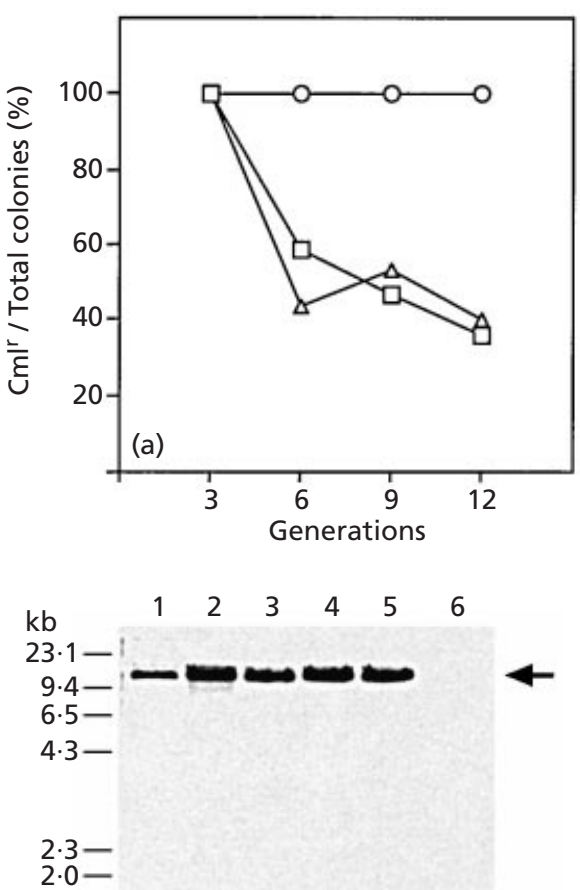

(b)

Fig. 3. Behaviour of pHT128 in N. meningitidis. (a) Stability of maintenance of pHT128 in N. meningitidis strain NIID57 ( $\square$, experiment $1 ; \triangle$, experiment 2 ) and in $E$. coli strain LE392 (O) in drug-free liquid culture. (b) Southern blotting using a cat gene as a probe. The bacteria were cultured under the same conditions as above except for the presence of chloramphenicol. DNA samples were isolated as described in Methods. Lanes: 1, Clal-digested pHT128 as a positive control; 2, Clal-digested total DNA isolated from bacterial culture at the third generation; 3 , at the sixth generation; 4 , at the ninth generation; 5 , at the twelfth generation; 6 , chromosomal DNA isolated from NIID57 as a negative control. The arrow indicates linearized $\mathrm{pHT} 128$.

colonies examined and the amount of plasmid DNA from N. meningitidis was as much as that in E. coli DH5 $\alpha$ when examined by the density on agarose gel (data not shown). These results indicated that pHT128 could be conjugationally transferred from E. coli to $N$. meningitidis and existed at about 10 copies in $N$. meningitidis, as much as in E. coli.

\section{Stability of pHT128 in $N$. meningitidis}

To check the stability of pHT128 in N. meningitidis, we successively subcultured $N$. meningitidis harbouring pHT128 in liquid medium and counted total c.f.u. on GC agar plates with or without $5 \mu \mathrm{g}$ chloramphenicol $\mathrm{ml}^{-1}$ as described in Methods. Although pHT128 was maintained at a frequency of $100 \%$ in E. coli strain LE392 even in drug-free liquid medium, the plasmid was gradually lost from $N$. meningitidis at a rate of about 7-9\% loss per generation under the same conditions (Fig. 3a). This result indicated that maintenance of pHT128 in N. meningitidis was relatively unstable in the absence of selection by chloramphenicol. 
(a)

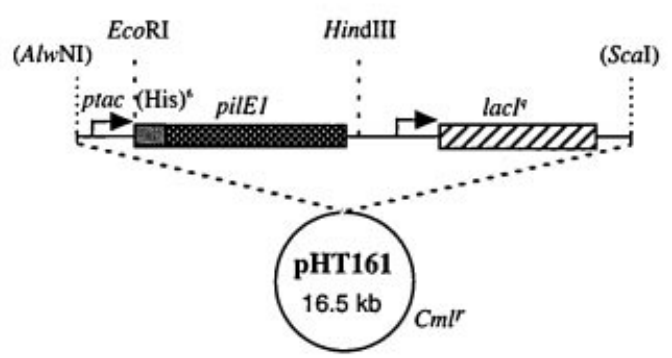

(b)

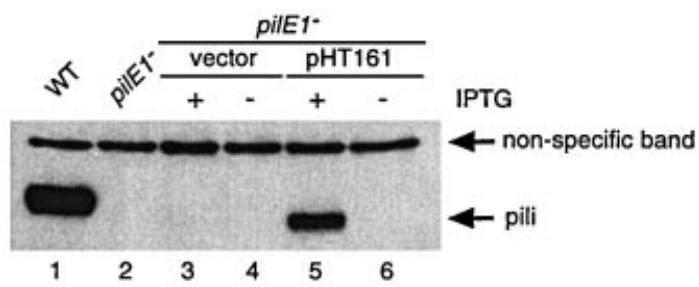

(c)

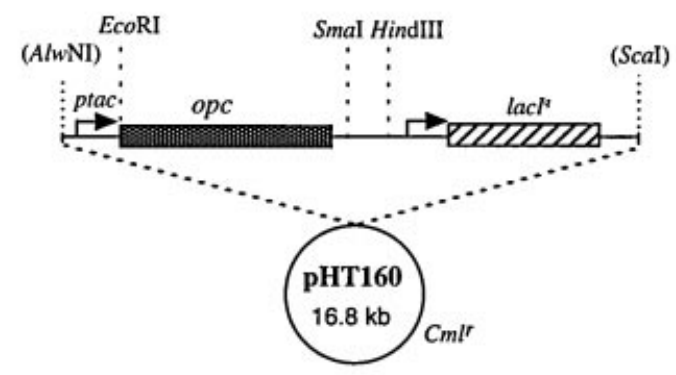

(d)

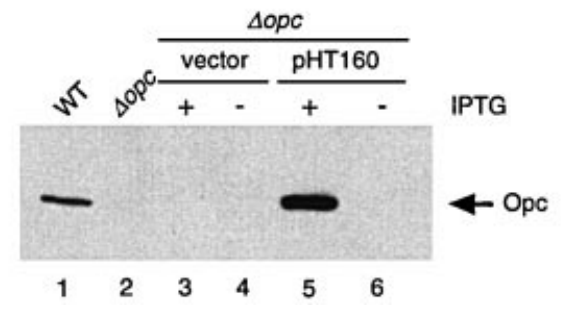

Fig. 4. Western blotting of $N$. meningitidis transconjugants. (a) Structure of pHT161. A histidine tag was attached to the 5'-terminus of the pilE1 structural gene. (b) Western blotting using anti-pili serum. Lanes: 1, NIID57; 2, HT1033; $3, \mathrm{HT} 1033$ harbouring $\mathrm{pHT} 128$ cultured in the presence of IPTG; 4, HT1033 harbouring pHT128 cultured in the absence of IPTG; 5, HT1033 harbouring PHT161 cultured in the presence of IPTG; 6, HT1033 harbouring pHT161 cultured in the absence of IPTG. The lower band corresponds to pili. The upper band is a non-specifically reacted band that was used as an internal control. (c) Structure of pHT160. (d) Western blotting using anti-Opc monoclonal antibody, B306. Lanes: 1, H44/76; 2, HT1037; 3, HT1037 harbouring pHT128 cultured in the presence of IPTG; 4, HT1037 harbouring pHT128 cultured in the absence of IPTG; 5, HT1037 harbouring PHT160 cultured in the presence of IPTG; 6, HT1037 harbouring PHT160 cultured in the absence of IPTG.

To further study whether pHT128 was maintained as an episome, we isolated total DNA from bacteria cultured in the presence of chloramphenicol and performed
Southern blotting using the chloramphenicol acetyltransferase (cat) gene as a probe. A band corresponding to linearized pHT128 was detected from the samples at each cell generation tested and no other bands could be seen (Fig. 3b). This result showed that pHT128 was maintained in N. meningitidis as a plasmid.

\section{The extraneous genes on pHT128 can be expressed in N. meningitidis}

Next, we examined whether pHT128 vector is available for the complementation of mutations in $N$. meningitidis. A derivative of $\mathrm{pHT} 128$ carrying the $\mathrm{His}_{6}$ tagged pilE1 or the opc gene under the control of tac promoter, pHT161 or pHT160, respectively (Fig. 4a, c), was introduced into N. meningitidis strain HT1033 (pilE1) or HT1037 $(\Delta o p c)$. Cell lysates of $\mathrm{Cml}^{\mathrm{r}}$ transconjugants cultured in the presence and absence of IPTG were examined for the expression of pili and Opc protein by Western blotting with each antibody. As shown in Fig. 4(b, d), pili or Opc protein were expressed in N. meningitidis under the control of IPTG induction. These results confirmed that the foreign genes on pHT128 could be expressed in N. meningitidis.

\section{Mobilization of the plasmids is independent of neisserial natural competence}

To confirm that the mobilization of the plasmids observed in this study was independent of natural competence, we performed triparental conjugation using the pilE1-defective strain HT1033 as recipient, since the product of pilE1, pili, is essential for natural competence (Jyssum \& Lie, 1965). The mean conjugation efficiency to the pilE1-defective strain was $6 \cdot 8 \times 10^{-6}$, which was not lower but rather higher than that to a wild-type strain $\left(3 \cdot 0 \times 10^{-6}\right)$, for unknown reasons. This result showed that the conjugational transfer of plasmid from E. coli to N. meningitidis was not dependent on neisserial natural competence.

\section{DISCUSSION}

Genetical tools for Neisseria species have been mainly developed in N. gonorrhoeae (Stein et al., 1983; Piffaretti et al., 1988; Roberts, 1989) and there are few efficient genetic tools such as transposons and plasmids that work in N. meningitidis. Transposons derived from Streptococcus faecalis, Tn916 (Kathariou et al., 1990; Stephens et al., 1991; Erwin \& Stephens, 1995) and Tn1545- 3 (Nassif et al., 1991) were applied to $N$. meningitidis for random mutagenesis. In the case of plasmids, one R-plasmid in N. gonorrhoeae could be introduced into $N$. meningitidis by conjugation (Ikeda et al., 1986), but no further information has been reported so far. pMGC10, a derivative of a shuttle vector between E. coli and N. gonorrhoeae, was successfully mobilized to N. meningitidis (Nassif et al., 1991) and this was the only plasmid that was proved to work in $N$. meningitidis. However, this plasmid was constructed to introduce Tn1545- $\Delta 3$ into $N$. meningitidis and has not been commonly used as a plasmid vector available in 
N. meningitidis. Plasmids named $\mathrm{pJS}-\mathrm{A}$ and $\mathrm{pJS}-\mathrm{B}$ have been recently found in $N$. meningitidis (Hilse et al., 2000; Claus et al., 2001), but they might not be suitable for plasmid vectors in N. meningitidis because these plasmids, that were release-forms from the genome, seemed to be unstable as episomes. In this study, we showed that pHT128, a derivative of an IncQ broadhost-range vector, could be introduced into $N$. meningitidis at a considerable frequency and that it worked as a cloning vector in N. meningitidis in the presence of antibiotic. To our knowledge this is the first observation that an artificial plasmid can work well in N. meningitidis.

The difficulties of introducing R-plasmids into $N$. meningitidis may be partially attributed to some restriction/modification systems in $N$. meningitidis because naked DNA isolated from $N$. meningitidis transconjugants, but not from E. coli, could be easily transformed into $N$. meningitidis by electroporation (unpublished data). The influence of the restriction/ modification systems on the efficiency of conjugation is still controversial (Stein et al., 1988; Butler \& Gotschlich, 1991). However, mobilization of plasmid by conjugation from $E$. coli to $N$. meningitidis may circumvent the barrier of modification/restriction systems by some unknown mechanism(s) because pHT128 or pMGC10 (Nassif et al., 1991) was transferred at a considerable frequency.

The efficiency of plasmid DNA transfer in triparental conjugation was variable (Fig. 2). This might have been due to the difference of living state of $N$. meningitidis used for the preparation of recipient cells because neisseriae have rapid autolytic properties, even if cultured under steady conditions. In order to increase the transfer frequency, it would be critical to improve the recipiency of $N$. meningitidis.

To date, genetical analyses such as complementation tests in N. meningitidis have never been done because there were few useful plasmid vectors for $N$. meningitidis. We have shown here that pHT128 is applicable for complementation tests in N. meningitidis. We believe that our findings increase the possibilities for the molecular biological analysis of $N$. meningitidis.

\section{ACKNOWLEGMENTS}

We thank Dr T. Kuroki and Dr S. Yamai of Kanagawa Prefectural Public Health Laboratory for generously donating us N. meningitidis strains and providing instructions on the manipulation of Neisseria. We also thank Dr M. Achtman for generously donating mAb B306. This work was supported by grants from the Ministry of Health, Welfare and Labor.

\section{REFERENCES}

Achtman, M., Neibert, M., Crowe, B. A. \& 8 other authors (1988). Purification and characterization of eight class 5 outer membrane protein variants from a clone of Neisseria meningitidis serogroup A. J Exp Med 168, 507-525.

Barth, P. T. \& Grinter, N. J. (1974). Comparison of the deoxy- ribonucleic acid molecular weights and homologies of plasmids conferring linked resistance to streptomycin and sulfonamides. J Bacteriol 120, 618-630.

Barth, P. T., Tobin, L. \& Sharpe, G. S. (1981). Development of broad host range plasmid vectors. In Molecular Biology, Pathogenicity and Ecology of Bacterial Plasmids, pp. 439-448. Edited by S. B. Levy, R. C. Clowes \& E. L. Koenig. New York: Plenum.

Bhatti, A. R., O’Hara, K., White, L. A. \& Bryan, L. E. (1981). Presence of plasmid deoxyribonucleic acid in Neisseria meningitidis. FEMS Microbiol Lett 10, 175-177.

Butler, C. A. \& Gotschlich, E. C. (1991). High-frequency mobilization of broad-host-range plasmids into Neisseria gonorrhoeae requires methylation in the donor. J Bacteriol 173, 5793-5799.

Claus, H., Stoevesandt, J., Frosch, M. \& Vogel, U. (2001). Genetic isolation of meningococci of the electrophoretic type 37 complex. J Bacteriol 183, 2570-2575.

Dehio, C., Gray-Owen, S. D. \& Meyer, T. F. (1998). The role of neisserial opa proteins in interactions with host cells. Trends Microbiol 6, 489-495.

Dillon, J. R., Pauze, M. \& Yeung, K.-H. (1983). Spread of penicillinase-producing and transfer plasmids from the gonococcus to Neisseria meningitidis. Lancet 1 (8328), 779-781.

Erwin, A. L. \& Stephens, D. S. (1995). Identification and characterization of auxotrophs of Neisseria meningitidis produced by Tn916 mutagenesis. FEMS Microbiol Lett 127, 223-228.

Facinelli, B. \& Varaldo, P. E. (1987). Plasmid-mediated sulfonamide resistance in Neisseria meningitidis. Antimicrob Agents Chemother 31, 1642-1643.

Genco, C. A., Knapp, J. S. \& Clark, V. L. (1984). Conjugation of plasmids of Neisseria gonorrhoeae to other Neisseria species: potential reservoirs for the $\beta$-lactamase plasmid. J Infect Dis 150, 397-401.

Hass, R., Karhs, A. F., Facius, D., Allmeier, H., Schmitt, R. \& Meyer, T. F. (1993). TnMax - a versatile mini-transposon for the analysis of cloned genes and shuttle mutagenesis. Gene 130, 23-31.

Hilse, R., Stoevesandt, J., Caugant, D. A., Claus, H., Frosch, M. \& Vogel, U. (2000). Distribution of the meningococcal insertion sequence IS1301 in clonal lineages of Neisseria meningitidis. Epidemiol Infect 124, 337-340.

Ikeda, F., Tsuji, A., Kaneko, Y., Nishida, M. \& Goto, S. (1986). Conjugal transfer of beta-lactamase-producing plasmids of Neisseria gonorrhoeae to Neisseria meningitidis. Microbiol Immunol 30, 737-742.

Ison, C. A., Bellinger, C. M. \& Walker, J. (1986). Homology of cryptic plasmids of Neisseria gonorrhoeae with plasmids from Neisseria meningitidis and Neisseria lactamica. J Clin Pathol 39, 1119-1123.

Jyssum, K. \& Lie, S. (1965). Genetic factors determining competence in transformation of Neisseria meningitidis. 1. A permanent loss of competence. Acta Pathol Microbiol Scand 63, 306-316.

Kado, C. I. \& Liu, S.-T. (1981). Rapid procedure for detection and isolation of large and small plasmids. J Bacteriol 145, 1365-1373.

Kathariou, S., Stephens, D. S., Spellman, P. \& Morse, S. A. (1990). Transposition of Tn916 to different sites in the chromosome of Neisseria meningitidis: a genetic tool for meningococcal mutagenesis. Mol Microbiol 4, 729-735.

Knapp, J. S., Johnson, S. R., Zenilman, J. M., Robert, M. C. \& Morse, S. A. (1988). High-level tetracycline resistance resulting from TetM in strains of Neisseria spp., Kingella denitrificans, and Eikenella corrodens. Antimicrob Agents Chemother 32, 765-767. 
Kupsch, E.-M., Aubel, D., Gibbs, C. P., Kahrs, A. F., Rudel, T. \& Meyer, T. F. (1996). Construction of Hermes shuttle vectors: a versatile system useful for genetic complementation of transformable and non-transformable Neisseria mutants. Mol Gen Genet 250, 558-569.

Meyer, R., Laux, R., Boch, G., Hinds, M., Bayly, R. \& Shapiro, J. A. (1982). Broad-host-range IncP-4 plasmid R1162: effects of deletions and insertions on plasmid maintenance and host range. J Bacteriol 152, 140-150.

Nassif, X. \& So, M. (1995). Interaction of pathogenic neisseriae with nonphagocytic cells. Clin Microbiol Rev 8, 376-388.

Nassif, X., Puaoi, D. \& So, M. (1991). Transposition of Tn1545- $\Delta 3$ in the pathogenic neisseriae: a genetic tool for mutagenesis. J Bacteriol 173, 2147-2154.

Nassif, X., Pujol, C., Morand, P. \& Eugene, E. (1999). Interactions of pathogenic Neisseria with host cells. Is it possible to assemble the puzzle? Mol Microbiol 32, 1124-1132.

Pansegrau, W. \& Lanka, E. (1987). Conservation of a common 'backbone' in the genetic organization of the IncP plasmids RP4 and R751. Nucleic Acids Res 15, 2385.

Piffaretti, J.-C., Arini, A. \& Frey, J. (1988). pUB307 mobilizes resistance plasmids from Escherichia coli into Neisseria gonorrhoeae. Mol Gen Genet 212, 215-218.

Pintado, C., Salvador, C., Rotger, R. \& Nombela, C. (1985). Multiresistance plasmid from commensal Neisseria strains. Antimicrob Agents Chemother 27, 120-124.

Roberts, M. C. (1989). Plasmids of Neisseria gonorrhoeae and other Neisseria species. Clin Microbiol Rev 2, Suppl. S18-S23.

Rotger, R., Rubio, F. \& Nombela, C. (1986). A multi-resistance plasmid isolated from commensal Neisseria species is closely related to the enterobacterial plasmid RSF1010. J Gen Microbiol 132, 2491-2496.

Ryll, R. R., Rudel, T., Scheuerpflug, I., Barten, R. \& Meyer, T. F. (1997). PilC of Neisseria meningitidis is involved in class II pilus formation and restores pilus assembly, natural transformation competence and adherence to epithelial cells in PilC-deficient gonococci. Mol Microbiol 23, 879-892.
Sharpe, G. S. (1984). Broad host range cloning vectors for Gramnegative bacteria. Gene 29, 93-102.

Stark, M. J. R. (1987). Multicopy expression vectors carrying the lac repressor gene for regulated high-level expression of genes in Escherichia coli. Gene 51, 255-267.

Stein, D. C. (1989). Introduction of cloned genes into Neisseria gonorrhoeae. Clin Microbiol Rev 2, Suppl. S146-S149.

Stein, D. C., Silver, L. E., Clark, V. L. \& Young, F. E. (1983). Construction and characterization of a new shuttle vector, pLES2, capable of functioning in Escherichia coli and Neisseria gonorrhoeae. Gene 25, 241-247.

Stein, D. C., Gregoire, S. \& Piekarowicz, A. (1988). Restriction of plasmid DNA during transformation but not conjugation in Neisseria gonorrhoeae. Infect Immun 56, 112-116.

Stephens, D. S., Swartley, J. S., Kathariou, S. \& Morse, S. A. (1991). Insertion of Tn916 in Neisseria meningitidis resulting in loss of group B capsular polysaccharide. Infect Immun 59, 4097-4102.

Suker, J., Feavers, I. M., Achtman, M., Morelli, G., Wang, J.-F. \& Maiden, M. C. J. (1994). The porA gene in serogroup A meningococci: evolutionary stability and mechanism of genetic variation. Mol Microbiol 12, 253-265.

Virji, M. \& Heckels, J. E. (1983). Antigenic cross-reactivity of Neisseria pili: investigations with type- and species-specific monoclonal antibodies. J Gen Microbiol 129, 2761-2768.

Virji, M., Heckels, J. E., Potts, W. J., Hart, C. A. \& Saunders, J. R. (1989). Identification of epitopes recognized by monoclonal antibodies SM1 and SM2 which react with all pili of Neisseria gonorrhoeae but which differentiate between two structural classes of pili expressed by Neisseria meningitidis and the distribution of their encoding sequences in the genomes of Neisseria spp. J Gen Microbiol 135, 3239-3251.

Vogel, U. \& Frosch, M. (1999). Mechanisms of neisserial serum resistance. Mol Microbiol 32, 1133-1139.

Received 8 June 2001; revised 27 August 2001; accepted 4 September 2001. 